\title{
Evaluation of the association between polymorphisms at the DRD2 locus and stuttering
}

\author{
Journal of Human Genetics (2011) 56, 472-473; doi:10.1038/jhg.2011.29; published online 10 March 2011
}

Based on the report of Lan et al., ${ }^{1}$ we sought to replicate the association between stuttering and single-nucleotide polymorphisms (SNPs) that reside in the dopamine D2 receptor (DRD2) gene in additional populations. The only individual significant association observed by Lan et al. was with the $\mathrm{C}$ allele of rs6277, a synonymous SNP (Pro319Pro) within the coding sequence of this gene. In their Han Chinese sample of 112 cases and 112 controls, this allele occurred at a frequency of 0.96 in cases and 0.88 in controls, with a reported $P$-value of 0.001 .

We studied this polymorphism as well as another DRD2 synonymous SNP, rs6275, also studied by Lan et al., in two additional casea larger sample. The first was a group of 50 cases and 50 sex-matched controls of mixed ancestry $^{2}$ from Sao Paulo State, Brazil, while the second was a group of 214 cases and 451 control populations that together represented

neurologically normal controls of western European origin. ${ }^{3}$ All subjects provided written informed consent under institutionally approved human subjects research protocols. Speech diagnosis was performed using the Stuttering Severity Instrument, 3rd Edition (SSI-3), ${ }^{4}$ and as previously described. ${ }^{3}$ Genotypes were determined by dye terminator sequencing of both strands using an $\mathrm{ABI}$ 3730 XL capillary instrument.

Our first analysis determined that the genotypes at rs6277 and rs6275 did not deviate significantly from Hardy-Weinberg equilibrium expectation in either Brazilian $(P=0.60, \quad P=0.62)$ or western European populations $(P=0.59, P=0.43)$. The genotypic distributions we observed are shown in Table 1. In these populations, no significant differences between cases and controls were observed for allele frequencies of rs6277 $(P=0.26$ in the Brazilian population and

Table 1 Allelic association test for two SNPs in DRD2 with susceptibility of stuttering

\begin{tabular}{|c|c|c|c|c|c|c|}
\hline & \multicolumn{2}{|c|}{ Caucasian } & \multicolumn{2}{|c|}{ Chinese } & \multicolumn{2}{|c|}{ Brazilian } \\
\hline & $\begin{array}{l}\text { Controls } \\
(\mathrm{N}=451)\end{array}$ & $\begin{array}{c}\text { Cases } \\
(\mathrm{N}=214)\end{array}$ & $\begin{array}{l}\text { Controls } \\
(\mathrm{N}=112)\end{array}$ & $\begin{array}{c}\text { Cases } \\
(\mathrm{N}=112)\end{array}$ & $\begin{array}{l}\text { Controls } \\
(\mathrm{N}=50)\end{array}$ & $\begin{array}{l}\text { Cases } \\
(\mathrm{N}=50)\end{array}$ \\
\hline \multicolumn{7}{|c|}{ rs6275 (C/T) } \\
\hline $\mathrm{CC}$ & 234 & 99 & 17 & 19 & 19 & 20 \\
\hline CT & 178 & 91 & 63 & 62 & 26 & 22 \\
\hline TT & 39 & 24 & 32 & 31 & 5 & 8 \\
\hline$T$ freq. & 0.28 & 0.32 & 0.57 & 0.55 & 0.36 & 0.38 \\
\hline$P$ value & \multicolumn{2}{|c|}{0.13} & \multicolumn{2}{|c|}{0.78} & \multicolumn{2}{|c|}{0.77} \\
\hline \multicolumn{7}{|c|}{ rs6277 (T/C) } \\
\hline TT & 142 & 59 & 3 & 0 & 11 & 9 \\
\hline $\mathrm{TC}$ & 214 & 104 & 22 & 8 & 28 & 24 \\
\hline $\mathrm{CC}$ & 95 & 51 & 87 & 104 & 11 & 17 \\
\hline C freq. & 0.45 & 0.48 & 0.88 & 0.96 & 0.50 & 0.58 \\
\hline$P$ value & \multicolumn{2}{|c|}{0.25} & \multicolumn{2}{|c|}{0.001} & \multicolumn{2}{|c|}{0.26} \\
\hline
\end{tabular}

Abbreviations: DRD2, dopamine D2 receptor; SNP, single-nucleotide polymorphism.
$P=0.25$ in the western European population) or rs6275 ( $P=0.77$ and $P=0.13$, respectively). Analysis of haplotypes containing these two SNPs failed to show any significant association with stuttering $(P=0.11-0.77)$.

Our results differ substantially from those of Lan et al., who reported that the C allele of rs6277 is more frequent in cases than in controls. However, because this allele exists at a frequency of $88 \%$ in normal controls, it seems unlikely to be a significant contributor to stuttering by itself in the Han Chinese population, where stuttering has been estimated to occur in only $1 \%$ of adults. ${ }^{5}$ In addition, Lan et al. reported a somewhat paradoxical finding regarding rs6277 diplotypes. While homozygosity for the $\mathrm{C}$ allele was more common in cases $(92.9$ vs $77.7 \%$ in controls), having one copy of the $\mathrm{C}$ allele was more common in controls (19.6 vs $7.1 \%$ in cases). This would seem to suggest a situation in which the $\mathrm{C}$ allele carries a slightly increased risk when present in two copies but has a large opposite effect when present in one copy.

It is possible that an authentic association with rs6277 exists in Han Chinese (who speak Mandarin, a hieroglyphic language) but not in Brazilians or western Europeans (who speak alphabetic languages). In both our western European cohort and our Brazilian cohort, the C allele of rs6277 is much less frequent than in the Han Chinese, where it is the most common allele. This difference may help obscure the true extent of association more generally. However, our data do not support the conclusion that the C allele of rs6277 is associated with stuttering in general.

\section{ACKNOWLEDGEMENTS}

This work was supported by NIDCD Intramural Grant DC-000046-11 and by FAPESP \#2007/02561-9 
and \#2010/00501-1. We thank the stuttering research subjects for their participation.

Changsoo Kang ${ }^{1}$,

Bianca Santos Domingues ${ }^{2}$, Eduardo Sainz ${ }^{1}$, Carlos Eduardo Frigério Domingues ${ }^{2}$, Dennis Drayna ${ }^{1}$ and Danilo Moretti-Ferreira ${ }^{2}$

${ }^{1}$ National Institute on Deafness and Other Communication Disorders, National Institutes of Health, Bethesda, MD, USA and ${ }^{2}$ Department of Genetics, Bioscience Institute, Sao Paulo State University (Unesp), Botucatu, Brazil E-mail: drayna@nidcd.nih.gov

1 Lan, J., Song, M., Pan, C., Zhuang, G., Wang, Y., $\mathrm{Ma}, \mathrm{W}$. et al. Association between dopaminergic genes (SLC6A3 and DRD2) and stuttering among Han Chinese. J. Hum. Genet. 54, 457-460 (2009).
2 Lins, T., Vieira, R., Abreu, B., Grattapaglia, D. \& Pereira, R. Genetic composition of Brazilian population samples based on a set of twenty eight ancestry informative SNPs. Am. J. Hum. Biol. 22, 187-192 (2010).

3 Kang, C., Riazuddin, S., Mundorff, J., Krasnewich, D., Friedman, P., Mullikin, J. et al. Mutations in the lysosomal enzyme-targeting pathway and persistent stuttering. N. Engl. J. Med. 362, 677-685 (2010).

4 Riley, G. D. Stuttering Severity Instrument for Children and Adults 3rd edn (Pro-Ed, Austin, TX, 1994).

5 Bloodstein, 0 \& Ratner, N. B. A Handbook on Stuttering 6th edn (Thomson Delmar Learning, Clifton Park, NY, 2008) 